\title{
CONSTITUCIONALIZACIÓN DEL DERECHO CIVIL A TRAVÉS DE LA JURISPRUDENCIA DEL TRIBUNAL CONSTITUCIONAL PERUANO
}

\author{
MANUEL JESÚS MiRANDA CANALES*
}

\begin{abstract}
Resumen
El artículo evidencia cómo el Derecho Constitucional transciende a todo el ordenamiento jurídico y lo sujeta a sus disposiciones; constitucionalización que es fuertemente acentuada por la jurisprudencia del Tribunal Constitucional que complementa y fortalece las instituciones jurídicas del Derecho Civil, en particular del Derecho de Familia.
\end{abstract}

Palabras clave: Constitución, derecho civil, derecho de familia, Tribunal Constitucional, jurisprudencia.

\begin{abstract}
This article evidences the way of the Constitutional Law transcends the entire legal system and subjects to its provisions, constitutionalization which is stongly accentuated by the law of the Constitutional Court that complements and strengthens the legal institutions of Civil Law, in particular the family Law
\end{abstract}

Keywords: Constitution, civil law, family law, Constitutional Court, jurisprudence.

\section{Sumario}

1.- Introducción. 2.- Constitucionalización del Derecho 3.- La Constitución y el Derecho Civil. 4.El Derecho Civil en la interpretación de la jurisprudencia del Tribunal Constitucional. 5.Conclusiones. 6.- Bibliografía.

\section{Introducción}

La evolución de las ciencias jurídicas puede ser medida y contrastada en el dinamismo y crecimiento de sus instituciones. Son estas las que finalmente determinan la materialización del Derecho.

El Derecho constitucional no se encuentra exento de esta evolución, por el contrario, despliega todos sus efectos en el ordenamiento jurídico. A este proceso llamaremos constitucionalización del Derecho, toda vez que los efectos de nuestra Carta constitucional, se irradian en todas las ramas del Derecho. Así el Tribunal

* Vicepresidente del Tribunal Constitucional del Perú. Doctor en Derecho. Exconsejero del Consejo Nacional de la Magistratura. Exjuez de la CorteSuprema de Justicia de la República. 
Constitucional, ha determinado en la STC 0042-2004-AI/TC la existencia de un principio de constitucionalidad- y no solo de conformidad con la ley -principio de legalidad-. Ello es así, en la medida en que en nuestra Constitución están incorporados el principio de supremacía constitucional y el principio de fuerza normativa (artículo 51). La Constitución no es un mero documento político, sino también norma jurídica, lo cual implica que el ordenamiento jurídico nace y se fundamenta en la Constitución y no en la ley. El principio de fuerza normativa de la Constitución quiere decir que todos los llamados a aplicar el Derecho deben considerar a la Constitución como premisa y fundamento de sus decisiones (art. $38^{\circ}$ y $45^{\circ}$ de la Constitución); sin embargo, en el presente artículo, nos detendremos en el ámbito del Derecho Civil y, más concretamente, en el del Derecho de Familia.

Debemos reconocer la importancia de la transición de un Estado de Derecho a un Estado Constitucional de Derecho, y con este nuevo modelo, la acogida de un principio constitucional que se superpone al principio de legalidad, otrora eje del ordenamiento jurídico. Por ello, el presente artículo, también tiene como objetivo que el lector no pierda de vista algunos conceptos claves que le permitirán tener una perspectiva más completa de la materia.

Además, considero esencial destacar cómo el Tribunal Constitucional, en su rol de máximo intérprete de la Constitución y garante de los derechos fundamentales, debido a su jurisprudencia, ha ido dilucidando los conceptos de familia y matrimonio, dotándoles de nuevos contenidos que se ajustan a las nuevas exigencias de nuestra sociedad.

En ese sentido, el objeto del presente artículo no es otro que poner en evidencia que el Derecho Constitucional, hoy por hoy, transciende a todo el ordenamiento jurídico y lo sujeta a sus disposiciones. Esta labor de constitucionalización es fuertemente acentuada por el Tribunal Constitucional que, mediante su jurisprudencia, logra complementar y fortalecer las instituciones jurídicas del Derecho Civil, específicamente, del Derecho de Familia.

\section{Constitucionalización del Derecho}

Desde los albores del siglo XIX, el orden jurídico tuvo la Ley como eje central y esencial que condicionó el comportamiento de la sociedad de aquel entonces. En ese sentido, el Derecho establecía sus cimientos en el principio de legalidad, lo cual significaba que la Constitución, concebida como tal, no era otra cosa que una norma política, desprovista de contenido jurídico vinculante².

Desde mediados del siglo XX, el marco de referencia y parámetro del ordenamiento deja de ser la Ley, dando paso a una nueva etapa marcada por la Constitución, la que

2 LANDA, César. La constitucionalización del Derecho Peruano. PUCP, Revista de Derecho. Lima, 2013. № 71, p.14. 
fundamenta sus contenidos en valores y principios superiores, colocando a la persona humana como eje del sistema jurídico. Desde entonces, el concepto de Constitución ha transitado hacia una etapa en la que ya no quedan dudas sobre su carácter de norma jurídica suprema en el ordenamiento jurídico nacional.

Debemos, pues, reconocer que hoy día la Constitución ha logrado desplazar a la Ley como fuente primaria y plena del Derecho, y ha irradiado sus efectos de manera imperativa y directa sobre todos los poderes públicos y privados, sujetándolos al cumplimiento de sus mandatos. Sin embargo, como acertadamente lo recuerda el profesor César Landa, "no se trata solo de un cambio de posición jerárquica de las normas, sino que esta transición nos lleva a replantear la manera de entender el derecho, la jurisprudencia, la jurisdicción y el rol propio del juez a la luz de nuevos contenidos cuyo vértice es la protección de la persona humana" ${ }^{3}$. Es decir, que el fenómeno de constitucionalización del Derecho no solo ha afectado al carácter de la propia norma, sino también a la forma cómo se hace Derecho ya que los principios rectores que ahora lo regulan tienen su basamento en valores y principios cuya importancia radica en el respeto a los derechos fundamentales.

El término Constitucionalización del Derecho surgió, por primera vez, en la reunión de la Asociación Francesa de los Constitucionalistas, en Febrero de 1980, en la Facultad de Derecho de Saint - Maur, y tuvo como finalidad cambiar la concepción del Derecho, a fin de sujetarla a una regulación mucho más imperativa ${ }^{4}$. Por ello, se afirmó que la constitucionalización de las distintas ramas del Derecho marcó una quiebra en el tradicional modelo de Estado de Derecho para trasladarnos a uno nuevo, el Estado Constitucional de Derecho.

Conviene destacar cuál es la diferencia entre un ordenamiento constitucionalizado y otro que no lo es. La principal distinción radica en que en el último, la Constitución está limitada al ámbito de su carácter normativo y se erige, únicamente, como un documento cuyo contenido contempla un mero catálogo de disposiciones para regular una adecuada actuación estatal; funge como un orden marco que solo es funcional cuando se vislumbra una trasgresión de sus fines, que descriptivamente están determinados. En cambio, en un ordenamiento constitucionalizado se evidencia una estructura ordenada y fundamental que impone realizar determinadas acciones afirmativas y ya no solo restricciones a Estado privados.

PRIETO, Luis. “El constitucionalismo de los derechos". En Revista Española de Derecho Constitucional, 2004, p. 15.

4 FAVOREU, Louis. “Constitucionalización del Derecho". Universidad Austral de Chile. Revista de Derecho, Vol. XII, agosto 2001, p. 31. 
La constitucionalización del ordenamiento no es una cualidad "todo o nada", algo que se tiene o no se tiene en absoluto, sino que se configura como un proceso que admite grados o intensidades 5 .

$\mathrm{Al}$ respecto, es importante destacar los atributos y las facultades que acompañan al fenómeno de la constitucionalización del Derecho. En tal sentido, encontramos la Justicia constitucional, la Constitución sustantiva, la Constitución que está impregnada en todo el ordenamiento jurídico y la rigidez constitucional del caso.

\section{La rigidez constitucional}

La Rigidez Constitucional supone que cualquier reforma de la Constitución solo será posible si se cumple algún procedimiento previamente dispuesto para su aprobación, modificación o derogación. De este modo, al definir y cualificar al poder competente para la reforma de la Constitución, frente a otros poderes constituidos, se pretende garantizar la primacía constitucional. "Las constituciones rígidas y solamente ellas gozan de un régimen jurídico especial, diverso del que tienen las leyes, en el sentido de que el procedimiento de reforma de la Constitución es distinto al procedimiento de formación de las leyes"'.

Una Constitución sin rigidez terminaría abandonando todo en manos de las mayorías. Como señala Ferreres, una Constitución rígida genera en el legislador la capacidad de producir fundadas razones para el cambio constitucional7.

\section{La Justicia Constitucional (La garantía judicial de la Constitución)}

La justicia constitucional instituye formas de defensa de la Constitución, por ello se ha convertido en pilar angular para garantizar el respeto y el cumplimiento de sus dispositivos. Esta situación, obligó a que la Constitución se previera de mecanismos de tuición para garantizar el cumplimiento de los derechos fundamentales.

Hoy en día debemos reconocer que la importancia de la justicia constitucional es indiscutible, ya que gracias a esta, se garantiza el verdadero equilibrio de los poderes o, como modernamente se conoce, el de las funciones atribuidas a cada uno de los componentes del Estado.

Es oportuno señalar, para un mejor entendimiento del estudio, que como parte de estos mecanismos establecidos en la Constitución sea, tal vez, la forma más evidente en que el fenómeno se manifiesta como creciente protagonismo del Tribunal Constitucional (TC), supremo intérprete de la Constitución, que a través de sus

5 GUASTINI, Riccardo "La constitucionalización del ordenamiento jurídico: el caso italiano". Presentación de Miguel Carbonell. México, 2001, p.153.

6 GUASTINI, Riccardo. "Rigidez constitucional y límites a la reforma en el ordenamiento italiano". México, p. 175.

7 FERRERES, Víctor. “Una defensa de la rigidez constitucional”. En Doxa, N. . 23, año 2000, p. 39. 
sentencias, prevé la real significación de conceptos, derechos y principios jurídicos que repercuten desde el derecho tributario hasta los derechos humanos 8 .

Este proceso de Judicialización del Derecho, que se manifiesta en las funciones de los tribunales constitucionales, encargados de garantizar los derechos fundamentales, también se evidencia en el desarrollo del proceso de globalización internacional y regional el cual no solo es económica sino también política y social'9

En ese contexto, podemos aseverar que, el Tribunal Constitucional es el órgano llamado a impartir justicia constitucional, no solo porque dicha competencia le ha otorgado directamente la Carta Magna, sino también porque su razón de ser es vigilar principalmente el cumplimiento de los derechos fundamentales; labor será solo posible cuando el TC interprete los contenidos y alcances fundamentales de manera integrada, combinando las disposiciones constitucionales, con los valores y principios superiores de la sociedad.

Así, podemos evidenciar que la Constitución, a través de los elementos que la conforman, tanto en el reconocimiento de derechos, como en la estructura de Estado, establece los mecanismos de protección de su normativa potencial, concretizando, de esta forma, su eficacia (procesos constitucionales) y supremacía constitucionales.

De lo expuesto, podemos afirmar que tanto nuestro sistema de administración de justicia y la relación entre personas naturales y jurídicas, como también las instituciones públicas, inician la fundamentación de su razonamiento jurídico en la Constitución, debido a que, como lo ha establecido nuestro Tribunal Constitucional, "no existe área del derecho que esté exenta de su control", debido necesariamente a que tanto el Derecho como la Constitución, tienen como finalidad la tutela y defensa de los derechos fundamentales de la persona.

Por todo lo anterior, consideramos importante concluir con una cita de Cappelletti ${ }^{10}$ : "la Justicia Constitucional es la vida, la realidad y el porvenir de las Cartas Constitucionales de nuestra época".

\section{Constitución sustantiva}

En el Estado Constitucional, la Constitución se convierte en una norma con gran carga axiológica. Siguiendo a Aguiló, podemos afirmar que así como la Constitución estatuye una serie de instituciones y les otorga competencias (por ejemplo: Poder Ejecutivo, Congreso de la República, Poder Judicial, Tribunal Constitucional, etc.) también prescribe una "dimensión valorativa". Esto es, que aparte de los preceptos estrictamente normativos que tangiblemente los impone, también reconoce

Ib.1,p.13.

Ib.1,p.16.

10 CAPPELLETTI Mauro. La justicia constitucional y dimensiones de la justicia en el mundo contemporáneo. De UNAM, Facultad de Derecho, México, 2007. 
situaciones y valores igualmente importantes, tales como la soberanía popular, la dignidad y seguridad de las personas, la diversidad cultural, la educación, la salud pública11. La "rematerialización" de la Constitución implica que esta no solo determina cómo debe organizarse el poder para tomar sus decisiones sino qué es lo que puede o debe decidir ${ }^{12}$.

Si el sistema jurídico careciera de esta dimensión sustantiva, y fuera exclusivamente un conjunto de órdenes respaldadas por el imperio de la Ley, no podríamos hacer uso de el para resolver los conflictos entre valores que la propia Constitución encierra ${ }^{13}$. Por ello, debemos enfatizar que concebir la Constitución como una norma de contenido material -y no solo competencial- conlleva a una consecuencia práctica muy importante en el momento de efectuar el control constitucional, puesto que no solo serán constitucionalmente válidos aquellos actos emitidos por la autoridad competente y en ejercicio de sus funciones sino que será preciso también analizar el grado de afectación de una medida en un derecho fundamental.

\section{La Constitución impregnada en el ordenamiento jurídico}

La combinación de los dos últimos factores mencionados (materialización del ordenamiento y justicia constitucional), permite que la Constitución se encuentre "impregnada" a todo el ordenamiento, es decir, que sus efectos se desplieguen a todos los ámbitos de la vida social y jurídica. De este modo, los operadores jurídicos ya no acceden a la Constitución a través del legislador sino que lo hacen directamente; por cierto, la Constitución ha abarcado más ámbitos de relevancia social, y como resultado de ello, es difícil encontrar un problema jurídico que carezca de relevancia constitucional.

En este sentido, los preceptos constitucionales ya no solo actúan como límites sino como fuerzas expansivas reconocidas en la determinación del orden jurídico, por lo que es posible hablar del "orden jurídico como un desarrollo de las exigencias constitucionales". El contenido del orden jurídico legítimo ya no resultará explicable en términos de respeto de los límites y discrecionalidad entendida como libertad; sino en términos de una concreción de los derechos a partir de una "razonable" ponderación de bienes y principios constitucionales.

\section{La Constitución y el Derecho Civil}

Una vez explicado el proceso de constitucionalización del Derecho y cuál es el rol de los Tribunales Constitucionales en el ejercicio de la justicia constitucional, conviene analizar la incidencia que la Constitución tiene sobre el llamado Derecho de los privados, la del particular el Derecho Civil.

11 AGUILÓ, Joseph. “Sobre la Constitución del Estado constitucional”. En Doxa , N² 24, año 2001, p. 446-447.

12 Ib. 2, p 48 .

13 GASCÓN, Marina y Alfonso GARCíA. Laargumentación en el Derecho. Segunda edición, 2005. 
Debemos señalar que la constitucionalización del Derecho Civil no es otra cosa que la aplicación de las normas constitucionales, cuyos efectos recaen en la relación con los particulares.

De hecho, así viene sucediendo en nuestro ordenamiento, ya que si bien es cierto que el juez está sometido a la ley - principio de legalidad -, es verdad también que lo está, ante todo, a la Constitución - principio de constitucionalidad -. El juez realiza una aplicación constitucional de la ley a la vista del caso concreto, en la medida en que debe considerar conjuntamente las razones de la ley y las razones de la Constitución ${ }^{14}$.

La mejor garantía del goce y ejercicio de los derechos y libertades civiles se encuentra en su reafirmación en los derechos fundamentales. De allí que la reforma del Código Civil tendrá mayor arraigo en la medida en que se edifique como un Derecho civil constitucional ${ }^{15}$. Esto significaría que las normas de carácter legal o reglamentario deben guardar coherencia y sujeción a la Constitución, no solo en su aspecto formal, sino también, material; de modo que al aplicarlas a un caso particular se evidencie una afectación a un derecho fundamental.

Así, tanto la dignidad de la persona, como el libre desarrollo de su personalidad y el respeto a los derechos de los demás, imprimen su huella en la consolidación de la constitucionalización del Derecho Civil.

Como consecuencia de lo anterior, y tomando en consideración el carácter normativo de la Constitución, su incidencia en el ordenamiento civil resulta innegable, y llega a alcanzar de forma más o menos intensa, a sus contenidos e instituciones jurídicas. Esto significa que muchas figuras, reglas y derechos civiles tradicionales han sido constitucionalizados, imprimiendo un límite infranqueable para el legislador ordinario. En ese sentido, el Código Civil, como cuerpo normativo que guía las relaciones entre los privados, deberá interpretarse a la luz de los preceptos establecidos en la Constitución y la jurisprudencia, a fin de respetar las garantías fundamentales.

Sin perjuicio de lo expuesto, debemos resaltar que la reinterpretación de las normas civiles a la luz de la Constitución, ciertamente podría irrogar dificultades y excesos por parte de los operadores del Derecho, pues "un enfoque que extrema el principialismo constitucional y desliga los derechos de la ley"16 ocasiona severos conflictos para los Jueces civiles, toda vez que estos, al verse más vinculados a la Constitución que a la ley, podrían -en su potestad de intérpretes- sobrepasar los límites al inaplicar irrestrictamente preceptos legales so pretexto de una propia exégesis de la Constitución, "haciendo tambalear los principios de seguridad jurídica

14 Ib. 11, p. 42.

15 Ib. 6, p. 22.

16 ARAGÓN, Manuel. El Juez ordinario entre legalidad y constitucionalidad. Madrid, p. 185, 186. 
y certeza del Derecho, que constituyen hoy los pilares esenciales de un Estado democrático de Derecho" ${ }^{\prime 17}$.

Sin embargo, la situación antes descrita se corrige cuando el Tribunal Constitucional, en su rol de máximo intérprete de la Constitución, otorga pautas de observancia obligatoria (sentencias y precedentes vinculantes) que sirven como norte para la actuación de los jueces ordinarios. De esta manera, cuando los operadores ordinarios apliquen el derecho correspondiente, ciertamente estarán sujetos a los parámetros constitucionales, empero, gracias a la labor jurisdiccional del Tribunal Constitucional por lo que, se impedirá la comisión de abusos y arbitrariedades sustentadas en las particulares interpretaciones de la Constitución.

Así, pues, el Código Procesal Constitucional prevé, en el artículo VI del Título preliminar, la siguiente pauta: “(...) Los Jueces interpretan y aplican las leyes o toda norma con rango de ley y los reglamentos según los preceptos y principios constitucionales, conforme a la interpretación de los mismos que resulte de las resoluciones dictadas por el Tribunal Constitucional" (énfasis propio).

Siguiendo la misma línea, es oportuno precisar que el Derecho civil y sus disposiciones recogidas en el Código Civil, reciben influencia directa de la normativa constitucional y la jurisprudencia emitida por el Tribunal Constitucional en dicha materia, lo que permite la adaptación de las Instituciones civiles a los postulados constitucionales.

En ese contexto, algunos Tribunales del Poder Judicial, a la luz de la jurisprudencia emitida por el Tribunal Constitucional, han debido amoldar el sentido de sus resoluciones al contexto de cambio social. Ello no solo ha sucedido en los casos más polémicos y conflictivos para las relaciones entre ambos órganos, como son los de tutela de honor, intimidad y propia imagen, en donde la controversia suscitada entre el Tribunal Constitucional y la Corte Suprema ha llegado a alcanzar tintes relativos al orden público, sino también en otros, que aunque no encontraron eco alguno en los medios de comunicación, dejan de ser trascendentales para el perfeccionamiento de la tutela que el Derecho persigue dispensar a todas las personas ${ }^{18}$.

De esta forma, el Derecho Civil se encuentra en transición, debido a que el fenómeno de la Constitucionalización del Derecho adapta, modifica y dota de nuevos contenidos a las Instituciones que están involucradas. En ese sentido, sus elementos deberán estar en permanente armonía con la normativa constitucional y la labor interpretativa que realizan sus órganos jurisdiccionales a través de la jurisprudencia como fuente de derecho.

17 GUTIÉRREZ, Pilar. La constitucionalización del Derecho Civil. Año 2011, p. 76.

18 BARBER CÁRCAMO, Roncesvalles. La Constitución y el Derecho Civil. Universidad de la Rioja, REDUR. № 2. 
Como consecuencia de lo previamente señalado, debemos hacer hincapié en que la Constitución ha incidido de manera determinante en la rama del Derecho Civil, sobre todo, en aquellas áreas que tienen como eje a la persona.

Así, a manera de ilustración, desarrollaremos cuál ha sido el impacto de la jurisprudencia constitucional en el llamado Derecho de Familia, poniendo en notoria evidencia que la composición de la legislación civil actual, a través de sus reformas, ha trazado ciertas directrices que a continuación analizaremos.

Antes de ahondar en la materia, es conveniente reseñar como dato importante, los orígenes del Derecho de Familia y cuál ha sido sus aportes en el Derecho Comparado.

La constitucionalización del Derecho de Familia tiene sus orígenes en la Constitución de Weimar de 1919, la que en su artículo $119^{\circ}$ estableció que "El matrimonio, en tanto que fundamento de la vida social familiar y del mantenimiento y crecimiento de la nación, está bajo la protección especial de la Constitución. Se basa en la igualdad jurídica de ambos sexos. (...)". Con la misma tónica, propondré algunos ejemplos en el Derecho Comparado; tal es el caso de la Constitución Española de 1931 que estableció en su artículo $43^{\circ}$ que "La familia está bajo la salvaguardia especial del Estado. El matrimonio se funda en la igualdad de derechos para ambos sexos (...)"; del mismo modo, también podemos citar el ejemplo de la Constitución italiana de 1947, la que estipuló en su artículo $29^{\circ}$ que "El matrimonio se regulará en base a la igualdad moral y jurídica de los cónyuges, con los límites establecidos por la ley en garantía de la unidad familiar.", y en su artículo $31^{\circ}$ indicó que "La República estimulará, con medidas económicas y otras providencias, la formación de la familia y el cumplimiento de sus obligaciones, con particular atención en relación a las familias numerosas" 19 .

En el caso peruano, el Derecho de Familia fue por primera vez, regulado y conceptualizado en la Constitución de 1933, y con ella se logró garantizar, por primera vez, su protección por parte del Estado. Años más tarde, con la Constitución de 1979, el valor asignado a la familia tuvo mayor trascendencia pues se la reguló como una Institución civil y social, vinculándola de manera conexa al matrimonio ${ }^{20}$.

En lo que respecta a la Constitución de 1993, esta sigue la línea planteada por la Carta anterior, aunque con algunos cambios sustanciales, como la desvinculación del matrimonio como condición sine qua non para la existencia de la familia. Esto supone,

19 CóRDOVA, Álvaro. La perspectiva constitucional de la familia en la jurisprudencia del Tribunal Constitucional. Gaceta del Tribunal Constitucional, 2008, p. 4.

20 Constitución Política del Perú de 1979, artículo 5:

“El Estado protege el matrimonio y la familia como sociedad natural e institución fundamental de la Nación.

Las formas de matrimonio y las causas de separación y disolución son reguladas por la ley (...)”. 
la aceptación de nuevas formas de familia, formadas a partir de la unión de hecho o concubinato ${ }^{21}$.

\section{El Derecho Civil en la interpretación de la jurisprudencia del Tribunal Constitucional}

Desde la instauración de la Carta Constitucional de 1993, el Tribunal Constitucional ha podido desarrollar, en contadas ocasiones, el concepto de familia. Por ejemplo, puede evidenciarse en la sentencia del expediente No 2868-2004-PA/TC "José Antonio Álvarez Rojas", el desarrollo del ius connubii como potestad fundamental correspondiente el ámbito del derecho al libre desarrollo de la persona. En dicha sentencia, el Tribunal disgrega los conceptos de familia y de matrimonio como elementos otrora dependientes y explicita que "más que de unos derechos fundamentales a la familia y al matrimonio, en realidad, se trata de dos institutos jurídicos constitucionalmente garantizados (Fundamento 13). De este modo, la precitada sentencia hace referencia a los conceptos jurídicos siguientes:

“Uno de esos ámbitos de libertad en los que no cabe la injerencia estatal, porque cuentan con la protección constitucional que les dispensa el formar parte del contenido del derecho al libre desarrollo de la personalidad, ciertamente es el ius connubii. Con su ejercicio, se realiza el matrimonio como institución constitucionalmente garantizada $y$, con él (aunque no únicamente) (énfasis agregado), a su vez, también uno de los institutos naturales y fundamentales de la sociedad, como lo es la familia. Por consiguiente, toda persona, en forma autónoma e independiente, puede determinar cuándo y con quién contraer matrimonio (...)" (Fundamento 14)

Con el ánimo de desarrollar el presente artículo, nos detendremos en el análisis de la sentencia del expediente No. 9332-2006-PA/TC en la cual el Tribunal Constitucional hace una interpretación más exhaustiva sobre el artículo $4^{\circ}$ de la Constitución.

La mencionada sentencia versa sobre una demanda de amparo interpuesta contra el Centro Naval del Perú, porque la entidad demandada no otorgó el carnet familiar a la hija del demandante, toda vez que esta tenía la condición de hijastra del demandante. Por tal razón, el Tribunal Constitucional, en tutela de los Derechos fundamentales, declaró fundada la demanda, ordenando a la entidad demandada que no debía

21 Constitución Política del Perú de 1993:

Artículo $4^{\circ}$ : La comunidad y el Estado protegen (...) a la familia y promueven el matrimonio. Reconocen a estos últimos como institutos naturales y fundamentales de la sociedad. La forma del matrimonio y las causas de separación y de disolución son reguladas por la ley.

Artículo $5^{\circ}$ : La unión estable de un varón y una mujer, libres de impedimento matrimonial, que forman un hogar de hecho, da lugar a una comunidad de bienes sujeta al régimen de la sociedad de gananciales en cuanto sea aplicable. 
realizar distinción alguna entre el tratamiento que recibían los hijos del demandante y el de su correspondiente hijastra.

Así, el Tribunal Constitucional, de conformidad con lo estipulado en el artículo $4^{\circ}$ de la Constitución, reconoce a la familia como un instituto natural y fundamental de la sociedad; en virtud de ello, el Estado y la comunidad se ven obligados a prestarle especial protección; en consecuencia el Tribunal replantea los contenidos conceptuales de familia y matrimonio, a fin de que, bajo interpretaciones diversas, no se trasgredan derechos fundamentales.

Al respecto, resulta importante mencionar el tratamiento de la familia a nivel internacional, la que también recibe considerable atención porque se encuentra protegida y amparada como derecho humano; así, el soft law sostiene que los hombres y las mujeres, a partir de la edad núbil, tienen derecho - sin restricción motivada en la raza, nacionalidad o religión- a casarse y a fundar una familia, agregando que esta es un elemento natural y fundamental de la sociedad, por lo que "tiene derecho a la protección de la sociedad y del Estado" (subrayado agregado) Artículo $16^{\circ}$ de la Declaración Universal de los Derecho Humanos (fundamento 4).

Expuesto lo anterior, y desde una perspectiva constitucional, debe indicarse que la familia, al ser un instituto natural, se encuentra inevitablemente a merced de los nuevos contextos sociales, tales como la inclusión social y laboral de la mujer, la regulación del divorcio y su alto grado de incidencia, los grandes flujos migratorios del campo a las ciudad, entre otros aspectos. Todo esto ha significado una evolución de la estructura familiar tradicional, en la que esta, sentaba sus bases esencialmente en una estructura nuclear y bajo la dirección de un pater familias, hacia una figura más abierta, cuya conformación incorpora nuevos conceptos jurídicos sobre la noción de familia. Como consecuencia de ello, se han generado familias con estructuras distintas, como son las surgidas de las uniones de hecho, las mono parentales o las que en doctrina se han denominado familias reconstituidas (fundamento 7).

Conforme se señala en el fundamento 8 de la precitada sentencia, "no existe un acuerdo en doctrina sobre el nomen iuris de esta organización familiar, utilizándose diversas denominaciones tales como familias ensambladas, reconstruidas, reconstituidas, recompuestas, familias de segundas nupcias o familiastras. Son familias que se conforman a partir de la viudez o el divorcio. Esta nueva estructura familiar surge a consecuencia de un nuevo matrimonio o compromiso. Así, la familia ensamblada puede definirse como "la estructura familiar originada en el matrimonio o la unión concubinaria de una pareja en la cual uno o ambos de sus integrantes tienen hijos provenientes de una relación previa".

Así, en el caso de autos sí se puede afirmar que existe una relación "estable, pública y de reconocimiento que determina la oponibilidad de este núcleo familiar, al que evidentemente pertenece la hijastra" (fundamento 23). Empero, la Asociación 
demandada sostiene que la medida impuesta se respaldó en su normatividad interna, sustentada en sus prerrogativas de organizarse. Cabe rescatar, que en ningún modo, las prerrogativas otorgadas a las Asociaciones deberán atentar contra otros bienes jurídicos, sobre todo si estos ostentan mayor relevancia, como la constitución de una familia.

A partir de todo ello, el Tribunal infiere que si bien el matrimonio y la familia son conceptos íntimamente relacionados el uno con el otro, son a su vez diferenciables. "No cabe por lo tanto establecer una relación de dependencia entre ambos, debe distinguirse claramente el derecho al matrimonio del derecho a fundar familia"22.

\section{Conclusiones}

a) Recapitulando lo señalado a lo largo del presente artículo, podemos concluir que la constitucionalización del derecho es un fenómeno cuyas características permiten garantizar la permanencia y eficacia de la Constitución en el ordenamiento jurídico.

b) En esa línea, el abandono de un modelo estrictamente legalista ha facilitado que el legislador entienda el Derecho como una unidad sujeta a los parámetros establecidos en la Constitución, ya que, solo a partir de esta, los dispositivos normativos con que cuenta cada área del derecho, cobran un sentido cabal.

c) Dicho esto, debemos asumir que también el Derecho Civil está inmerso en el marco de los contenidos constitucionales y su actuación se rige bajo principios de constitucionalidad recogidos en la Carta fundamental. Empero, no solo se encuentra únicamente subordinado a estos mandatos supremos, sino que también está permanentemente dotado con el contenido constitucional que la jurisprudencia, por intermedio del Tribunal Constitucional, desarrolla y que permite que el Derecho Civil pueda ir transformándose acorde al dinamismo por el que atraviesa nuestra sociedad.

d) El Derecho de Familia es un claro ejemplo de lo expuesto, pues, la evolución de la Familia en la legislación nacional no ha sido siempre la misma, sino que ha ido de la mano con el desarrollo de los derechos fundamentales. Esto, ha permitido que sus alcances y preceptos lleguen a ocupar un espacio más amplio, con mayor proyección cuando hace referencia al pasado.

e) Así pues, la constitucionalización de esta institución ha permito que se aborden nuevos aspectos, dejando de lado algunas concepciones

$22 \mathrm{Ib} 17, \mathrm{p} .7$. 
tradicionales. Todo ello, ha permitido ampliar su margen de protección cuya razón de ser reposa en las nuevas necesidades sociales.

f) En suma, hoy por hoy, el fenómeno de la constitucionalización del derecho implica una acogida a preceptos constitucionales, cuyo centro es el respeto de los derechos fundamentales de la persona. En consecuencia, el respeto de las disposiciones emanadas de la Carta Constitucional deberá ser de obligatorio acatamiento para todos los poderes públicos y para las relaciones entre los privados.

\section{Bibliografía}

AGUILÓ, Joseph. Sobre la Constitución del Estado constitucional, en Doxa № 24, año 2001, p. 446, 447.

ARAGÓN, Manuel. El Juez ordinario entre legalidad y constitucionalidad. En UAM, Madrid, p. 185, 186

BARBER, Roncesvalles. La Constitución y el Derecho Civil. Universidad de la Rioja, REDUR. No 2 .

CóRDOVA, Álvaro. La perspectiva constitucional de la familia en la jurisprudencia del Tribunal Constitucional. En Gaceta del Tribunal Constitucional, 2008, p.4.

FAVOREU, Louis. Constitucionalización del Derecho. Universidad Austral de Chile, Revista de Derecho, Vol. XII, agosto 2001, p.31.

FERRERES, Víctor. Una defensa de la rigidez constitucional. En Doxa N. . 23, año 2000, p. 39.

GASCÓN, Marina y GARCÍA, Alfonso. La argumentación en el Derecho. Segunda edición, 2005, p. 42.

GARCÍA DE ENTERRÍA, Eduardo. La constitución como norma y el Tribunal Constitucional. Madrid, 1994, p. 11.

GARCíA Pelayo, Manuel. Derecho Constitucional Comparado. $4^{\circ}$ ed. Caracas, 2002, p. 33.

GOMES CAHOTILHO, José. Teoría de la Constitución. Dykinson, Madrid, p. 331.

GUASTINI, Riccardo. La constitucionalización del ordenamiento jurídico: el caso italiano. En UNAM- México, 2001, p. 153.

GUTIÉRREZ, Pilar. La constitucionalización del Derecho Civil. Año 2011, p. 76.

HeLLER, Hermann, Teoría del Estado. Madrid, 1998, p. 295.

LANDA, César. "La constitucionalización del Derecho Peruano". PUCP, Revista de Derecho. Lima, 2013. No71. P.14.

PRIETO, Luis. El constitucionalismo de los derechos. En REDC-Madrid, 2004, p. 49.

TAMAYO Jaramillo, Javier. La constitucionalización del derecho privado en Colombia, Revista Justicia y Derecho Nº 3, 2012. 